\title{
Determinants of breeders' participation to an indigenous cattle breeding program
}

\author{
Younouss Camara ${ }^{1,2}$ - Mamadou Ciss ${ }^{2} \cdot$ Nassim Moula ${ }^{1,3} \cdot$ Mouhamadou Moustapha Sissokho ${ }^{2}$ - Frédéric Farnir ${ }^{1,3}$. \\ Nicolas Antoine-Moussiaux ${ }^{1,3}$
}

Accepted: 5 August 2019/Published online: 21 August 2019

(C) INRA and Springer-Verlag France SAS, part of Springer Nature 2019

\begin{abstract}
Many cattle breeding programs were initiated in Africa to increase the productivity of indigenous cattle breeds. Most of these programs have failed, partly due to the lack of involvement of breeders. The present case study contributes to the understanding of such failures. The N'Dama cattle breeding program in Senegal was taken as a case study for an in-depth analysis of participation using mixed methods. Semi-structured interviews were conducted with 52 breeders: 26 who participated, 15 of whom recently resigned, and 27 who had never participated. Content and statistical analyses were conducted to evaluate the motivations of breeders and the factors influencing their participation in the breeding program. Results more particularly highlight the complexity of social issues within a breeding project, in face of classical determinants of adoption that are distance or production systems features. It pinpoints crucial levers of improvement, i.e., the management of animal property rights between the nucleus management and the participating breeders, the legitimacy of participants' representatives in cooperatives, and the strategic mobilization of member social networks. Also, adding on previous works of the authors, this study highlights the need to take better account of the dynamics of production systems, then paying sufficient attention to the objectives, preferences, and ongoing strategies of the breeders for the future. The present study is the first to highlight the added value of mixed methods to analyze innovation adoption and participation in a livestock breeding program, taking both into account the overall innovation drivers and dynamics tied to actors' strategies.
\end{abstract}

Keywords N'Dama cattle $\cdot$ Genetic improvement $\cdot$ Breeders' motivations $\cdot$ Mixed methods $\cdot$ Senegal

\section{Contents}

1 Introduction

2 Material and methods

2.1 Study area

2.2 Sampling and data collection

2.3 Data analysis

2.3.1 Content analysis of narratives

2.3.2 Statistical analysis of questionnaire data

Nicolas Antoine-Moussiaux

nantoine@uliege.be

1 Fundamental and Applied Research for Animals \& Health (FARAH), Sustainable Animal Production, Faculty of Veterinary Medicine, University of Liege, 4000 Liege, Belgium

2 Institut Sénégalais de Recherche Agricole, Bel Air, routes des hydrocarbures -, BP 3120 Dakar, Sénégal

3 Tropical Veterinary Institute, Faculty of Veterinary Medicine, University of Liege, 4000 Liege, Belgium
3 Results and discussion

3.1 Congruence with breeders' objectives, main motive for participation

3.2 The ambiguous role of social bonds

3.3 Institutional roots of trust and program's outreach

3.4 Competition, conflicts, and power relationships

3.5 Methodological insights

3.6 Highlight: a matter of trust

4 Conclusion

Acknowledgments

References

\section{Introduction}

At the end of colonization and in times of early independence, many cattle genetic improvement programs based on indigenous breeds were initiated in Africa (Fall et al. 1982). In the majority of cases, those programs have been developed as scientific research projects and lacked an involvement of 
breeders. Most of these programs have failed, partly due to this lack of involvement (Kosgey et al. 2006). Participation of livestock keepers is indeed recognized as essential to a sustainable management of animal genetic resources (Leroy et al. 2017). In the 1980s, attempts were thus conducted to actively involve breeders in program design in developing countries to improve the level of ownership (Diop et al. 1993; Bosso et al. 2007). Nevertheless, this ownership and participation remained low, translating into a low diffusion of elite germplasms into productive herds, if not into the cessation of the breeding program. Let us note that similar constraints are met in the development of crossbreeding programs in developing countries (Abdulai and Huffman 2005; Roschinsky et al. 2015). Understanding these constraints is needed to identify levers, conditions, and adapted strategy for the mounting of successful breeding programs. Therefore, the present study focuses on the question of the factors influencing the decision of breeders to participate in an indigenous cattle breeding program.

Farmers' participation in agricultural extension programs has been the subject of many studies, being tied to the question of the adoption of technical innovations. Hence, mobilizing a diversity of approaches, these studies have identified a variety of factors influencing the decision or behavior of farmers to participate in programs or adopt defined innovations. These factors are, for example, the farmer's personal characteristics, as education level, and those of the farm, analyzed through quantitative methods (Abdulai and Huffman 2005; Suvedi et al. 2017); the social, psychological, and institutional relationships, analyzed by qualitative method (Mankad et al. 2017); and conflicts or lack of communication between stakeholders, analyzed by mixed methods (Limon et al. 2014). Frameworks are also proposed to structure these factors and guide our understanding of farmers' behavior, as the theory of reasoned action and the theory of planned behavior, which are then associated to statistical approaches, quantifying behaviors and including psychological and sociological characteristics in the analysis of farmers' motivation to adopt an innovation or diversify their activities (Senger et al. 2017). In the case of genetic progress, Camara et al. (2019) mobilized multivariate analysis to highlight the need to analyze the adoption of pure-breeding or crossbreeding within the wider range of innovations farmers are developing and adopting with regards to evolving objectives and constraints.

This work focuses on the case study of a N'Dama cattle breeding program, which has been running in Kolda in southern Senegal for more than 40 years (Fig. 1). Farmers in this locality have long benefitted from a variety of research or development activities, among which the N'Dama cattle breeding program. Indeed, in addition to the livestock research activities carried out by the Zootechnical Research Centre (CRZ), other actors such as Non-Governmental Organizations (NGO), extension services, or state agencies are carrying out important development activities on livestock, agriculture, health, and building resilience. This strong exposure to external aid and interventions is hypothesized as having led breeders to form particular perceptions of these programs as well as expectations and structured strategies. Therefore, this case study is here chosen as a complex setting where participation to the program is potentially confronted with barriers of diverse nature. The N'Dama cattle breeding project appears as a particular case in point of the intermingling of social, economic, and technical aspects in determining the success or failure of a livestock program. Indeed, having started in 1972, the Casamance N'Dama cattle breeding program has been running along a closed nucleus scheme until 1991. In that year, the nucleus was opened to breeders' animals, mainly in an attempt to foster participation (Diop et al. 1993). This stage started with a testing period between 1991 and 1996. In 2009, a new attempt to stimulate farmers' involvement was conducted through the creation of the Cooperative of N'Dama cattle farmers (CASE N'Dama), under the financial support of the project funding the breeding program. In 2015, the project has been hit by a wave of resignation, with 15 out of the 26 participating breeders leaving the project.

The latter peculiar history, which suggests complex underlying processes, made it necessary to adopt an open, mixed method approach to deliver a satisfying understanding of the situation. Hence, to analyze the factors and motivations at play, two types of analysis are here mobilized. One is a content analysis of narratives of three categories of breeders, defined according to their relationship to the breeding program: participants, resigning breeders, and non-participants. The other mobilizes statistical methods, namely Fisher's exact test and logistic regression, to evaluate the influence of identified variables on the probability of participation of breeders in the breeding program. This association is considered as a relevant method to understand the factual characteristics of the subject of study and the normative considerations of the actors. On a similar basis, a number of scholars have called for the development of a rigorous framework for mixed methods (Baškarada and Koronios 2018), of which this study represents an original application to animal breeding program analysis.

\section{Material and methods}

\subsection{Study area}

The study was conducted in three districts of Kolda in Casamance, Senegal $\left(12^{\circ} 54^{\prime} \mathrm{N}, 14^{\circ} 57^{\prime} \mathrm{W}\right)$, within a $30-\mathrm{km}$ radius around in the Zootechnical Research Center (CRZ) of Kolda. These three rural districts are Dioulacolon, Medina Elhadji, and Sare Bidji, located at 10, 13, and $17 \mathrm{~km}$ from 


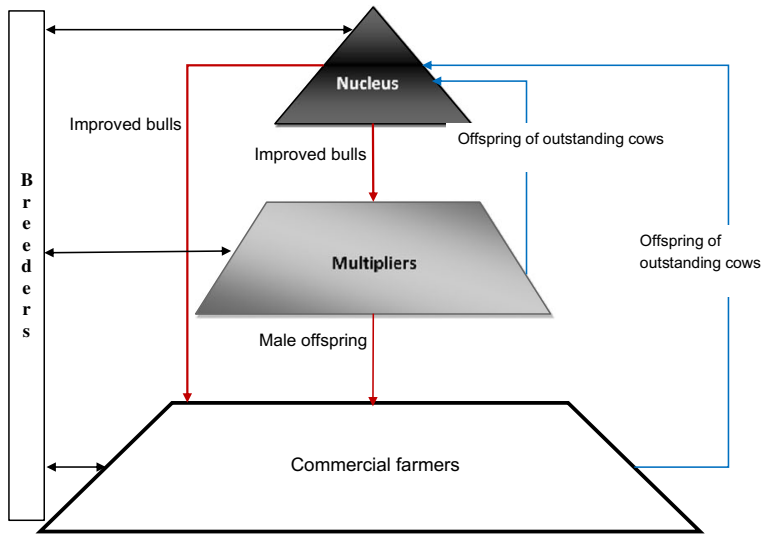

Breeding program scheme

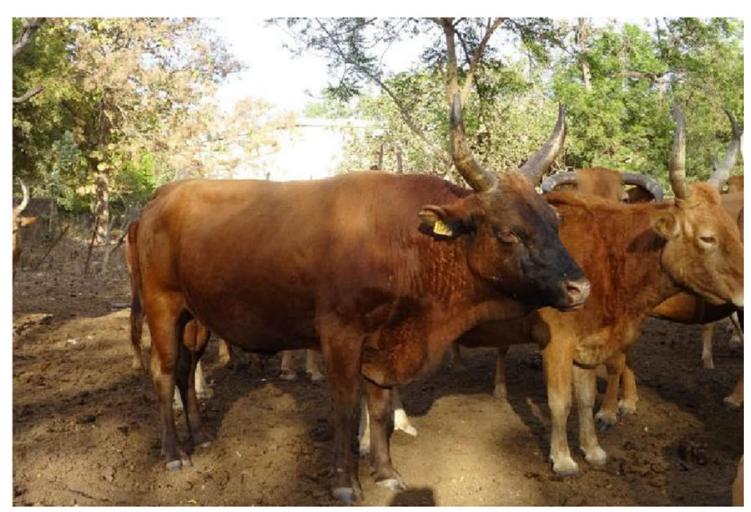

N'Dama sire product in the breeding nucleus

Fig. 1 Schematic representation of the N'Dama cattle three-tier breeding structure with levels of breeders' participation and possibly upward migration of genetic material

the CRZ, respectively. These districts are inhabited by a diversity of ethnic groups: the Fulani who are essentially pastoralists, the Mandingos who practice agriculture associated with some livestock (mainly cattle), and Diolas and Balantes, whose activities are agriculture associated with pig farming and forest exploitation.

The region presents a sub-humid tropical climate, characterized by a bimodal seasonal regimen. The average annual rainfall of $1000 \mathrm{~mm}$ is distributed over 5 months, from June to October. The predominant economic activities are agriculture, livestock, and forestry. The main livestock system is described as agro-pastoral, practicing crop-livestock integration in mixed rainfed agricultural systems. During the growing season, the animals graze in the forest and at the end of the harvest; they are parked on the fields. Animal manure is used for soil amendment and animal power is used for plowing. In turn, crop residues such as rice straw, millet or corn stalks, and cotton seeds are fed to animals. In addition to the N'Dama pure-breeding, breeders of this system practice crossbreeding (N'Dama cattle $\times$ Gobra cattle and N'Dama $\times$ exotic breed) for the production of animals for draught power, saving, and for meat and milk production (Camara et al. 2019). The second most common system is the grazing system. This system mainly rests on the use of the N'Dama cattle, preferred for its trypanotolerance (Camara et al. 2019).

In this region, the CRZ and CASE N'Dama develop a breeding program on the N'Dama cattle to improve meat production ability of this breed while preserving its trypanotolerance. These stakeholders organize the program on three tiers (Fig. 1): the breeding nucleus where improved bulls are produced (housed at the CRZ), the multiplication herd (kept by CASE N'Dama members), and the village herds where genetic progress has to be disseminated (commercial farmers).

\subsection{Sampling and data collection}

Interviewed breeders were selected following a dual sampling approach, using first a purposive then a respondent-driven sampling. Twenty-six breeders among those who collaborated with the CRZ were identified from the center's database (purposive sampling). These first respondents introduced us to breeders who had not collaborated with the CRZ (respondent-driven sampling). In total, 52 breeders were surveyed, corresponding to three groups concerning their involvement with the CRZ breeding program: those currently participating $(n=11)$, those who had resigned $(n=15)$, and those who never participated $(n=26)$. Invitations to contribute mentioned that the persons making decisions regarding cattle should be interviewed. Only men presented themselves at the interview meetings, being considered in the zone as the heads of households. No woman was included in the sample since no cattle-holding woman-lead household was identified in the present study.

Each interview was conducted in two phases. The first phase consisted of a semi-structured discussion aiming at collecting narratives of the breeders about their history of relationships with the breeding project. During this narrative, the interviewer eventually asked more in-depth questions to invite the interviewee to provide a more accurate account of their motives and their perception of program outputs, of meaningful events, and of responsibilities. In a second phase, data were systematically collected along a questionnaire including both categorical and numerical data. These survey variables were grouped into five broad categories, based on the first phase of preliminary open interviews with keystakeholders (breeder's organization) and literature (Abdulai and Huffman 2005; Suvedi et al. 2017). These categories are described here below: (1) farmer's characteristics, (2) farm characteristics, (3) objectives and desired production 
techniques, (4) institutional characteristics, and (5) access to services and markets. Face-to-face interviews with each farmer provided information on various aspects of each category, as detailed here below.

- Farmer characteristics - this category is composed of two categorical variables with three modalities each, i.e., place of residence (Dioulacolon, Sare Bidji, and Medina Elhadji) and main economic activity (livestock, agriculture, and trade), and a binary variable about education level (formal or no formal education);

- Farm characteristics - this category is composed of a quantitative variable, i.e., herd size (number of animals), and a binary variable, i.e., feed supplementation (yes or no);

- Production objectives and techniques - this category is composed of three categorical variables, i.e., breeders' objectives with six modalities (insurance, saving, income, cultural, traction, and manure), preferred breed with four modalities (N'Dama, Gobra, Djakore, and exotic crossbred), and genetic improvement with three modalities (N'Dama pure-breeding, N'Dama-Gobra crossbreeding, and exotic crossbreeding);

- Institutional relationships - this category is composed of three binary variables (yes or no), i.e., other relationship with CRZ, beneficiary of other programs, membership of a farmer organization;

- Distance to services and markets - this category is composed of three distances (in $\mathrm{km}$ ), i.e., from farm to CRZ, to livestock market and to dairy transformation unit.

The questions were administered in Fulani language (the language mostly spoken in the area). The responses collected were recorded, transcribed, and translated in French.

\subsection{Data analysis}

\subsubsection{Content analysis of narratives}

The first phase of interviews was subject to content analysis, conducted on translated transcripts based on the first steps of grounded theory (Strauss and Corbin 1990). Hence, following an open coding process, keywords and meaningful expressions were identified and grouped into categories. These categories related to distinct steps, modes, or aspects of the relationship between the interviewee and the breeding program. These rubrics were coded and filed in a spreadsheet (Excel Microsoft Office 2016). Part of this narrative information was subject to a visualization through the construction of frequency histograms. Hence, the motivations of the breeders for participating or not, and for resigning or maintaining in the program, have led to a descriptive statistical analysis along citation rates based on open coding outputs. In accordance with the principle of triangulation, stated information about facts, whether historical or contextual, was crosschecked between independent interviews.

\subsubsection{Statistical analysis of questionnaire data}

Statistical analysis was conducted in three steps. The first step consisted of an application of Fisher's exact test to evaluate dependence between each explaining variables and the project participation variable along its three modalities: current participants, resigning breeders, and non-participants. The Spearman correlation was also computed between all explaining variables. $p$ values under 0.05 were considered as statistically significant.

In the second step, a binary logistic regression model (questionr package, glm function, family = binomial) was used to analyze the relationship between the explaining variables and the participation variable (Suvedi et al. 2017). For this analysis, participation variable was transformed into a binary variable, distinguishing non-participants and participants (current and resigning). The merging of current participants and resigning breeders aims at focusing the analysis on the first participation of breeders in the breeding program, which is indeed common to both categories. The resigning processes are then tackled through Fisher's exact test (chosen due to limited numbers of observations by category once the three categories are considered separately) and content analysis. A series of univariate analyses was conducted for variable selection. Any variable with a $p$ value lower than 0.2 is considered as a potential determinant for the dependent variable under study and selected for the third step. The latter consisted of a progressive elaboration of a multivariate logistic regression model, through the stepwise method. The inclusion criterion was the Akaike information criterion (AIC), variables with an AIC lower than the AIC of the full model being removed (MASS package, stepAIC function). Through the process, it was checked that the selected explaining variables did not present significant correlations between them. All statistical analyses were performed using $\mathrm{R}$ software ( $\mathrm{R}$ Development Core Team 2017, version 3.5.1).

\section{Results and discussion}

In this section, narrative and statistical results will be reported simultaneously. Some of the narrative results will be mobilized in the interpretation of the statistical results, while some statistical outputs will be recalled or presented to discuss those of the narrative analysis. Figure 2 proposes a visual representation of motives for initiating, maintaining, resigning, and not participating in the program, based on citation rates as derived from open coding. 
Motives for participating

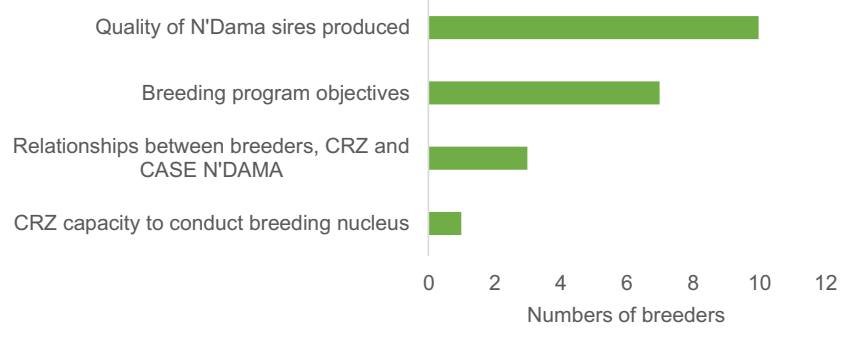

Motives for resigning

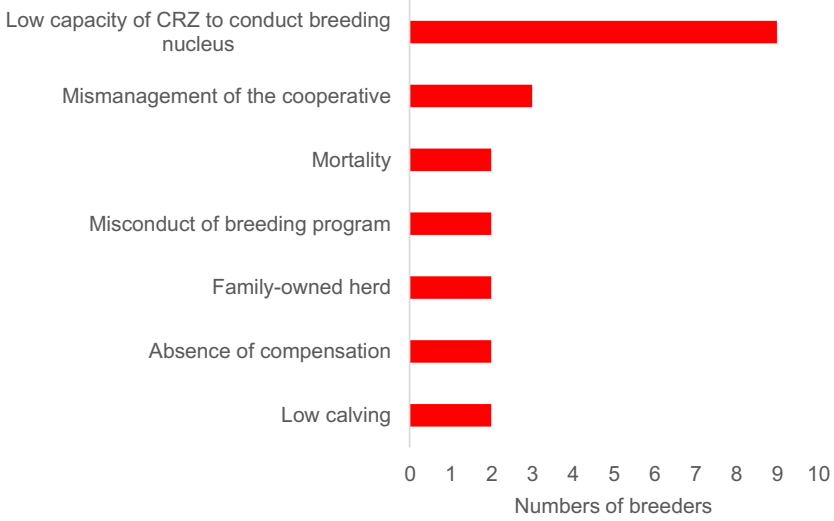

Fig. 2 Stated motives of breeders for participating, for maintaining, for resigning or not participating in the breeding program (number of citation, derived from open coding). CASE N'Dama, Coopérative des

\subsection{Congruence with breeders' objectives, main motive for participation}

The main motive for participation is the quality of animals produced at the breeding nucleus, being stated by almost all participating breeders. This motive explains also the continued adhesion of breeders. In their language, the quality of animals is synonymous with not only aesthetics but also resistance. "The tawny color of the sire's coat that I received allowed me to have products of the same coat." Indeed, this appearance will be key in determining the price of an animal on the market, "beautiful" animals then allowing breeders to meet certain financial needs through the sale of fewer heads. In addition, breeders keeping purebred N'Dama explained their interest for resistance by the low use of veterinary inputs and the good ability of this animal to graze in the forest, contrary to crossbreds. Animal resistance refers here more particularly to trypanotolerance, which is a major trait of N'Dama breed, i.e., its ability to produce under trypanosomian infestation.

In breeders' narratives, resistance is synonymous with herd growth and their ability to maintain a large herd with few inputs. However, despite the recurrence and importance of herd size in the decision of breeders as noticed by content analysis, the direct link between herd size and participation did not prove significant (Table 1). Nevertheless,
Motives for maintaining

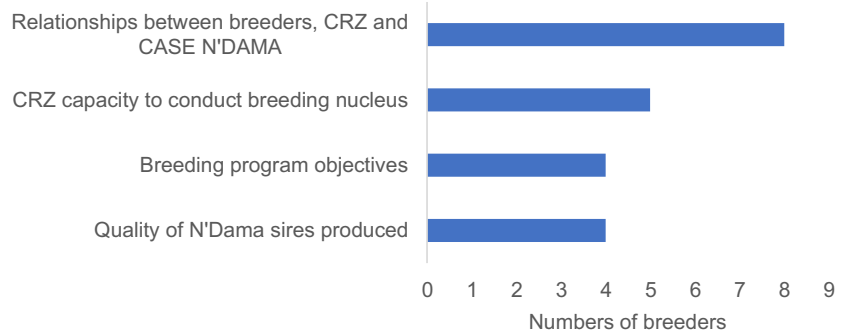

Motives for not participating

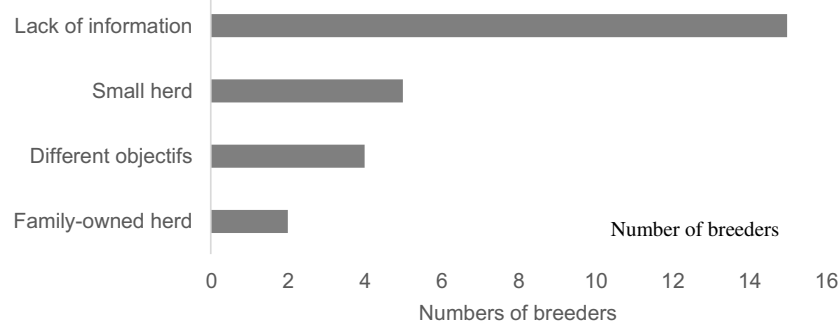

Agroéleveurs Sélectionneur du bovin N'Dama (Breeders Cooperative for N'Dama cattle breeding); CRZ, Centre de Recherche Zootechnique (Zootechnical Research Center)

both the herd size and the number of N'Dama cattle are significantly and positively tied to the number of animals sold (Spearman's test, $r=0.45$ and $r=0.4$, respectively), which was significantly linked to participation as shown by logistic regression (Table 2). This indirect link may be interpreted as highlighting the importance of savings and insurance objectives in traditional farming as well as the role of indigenous breeds in meeting these goals (Camara et al. 2019). Rather than resulting from a commercial logic, the sale of animals mainly aims at facing eventual financial needs. Farmers with larger herds feel more comfortable in selling cattle for a wider set of reasons, not only for extreme emergencies. Sale may also intervene as a tool to manage herd composition in terms of age and sex or as a reaction to animal diseases or injuries, thus reinforcing the link between offtake and herd size. This savings and insurance role is then rather played by resistant indigenous breeds, showing lower individual value, in both purebred and mixed herds (Stear et al. 2001; Traoré et al. 2018; Camara et al. 2019). The lower individual value comes as an explanation for the preferential destocking of these indigenous animals, which also means that more animals have to be sold to cover a given expense compared with crossbreds. Therefore, the adhesion of farmers to the N'Dama breeding program appears both statistically and narratively tied to this N'Dama-based livelihood strategy, translating into a 
Table 1 Distribution of breeders along surveyed variables and statistical link to participation variable and univariate logistic regression of factors determining breeder's participation in the N'Dama breeding program

\begin{tabular}{|c|c|c|c|c|c|c|c|c|c|}
\hline \multirow[t]{3}{*}{ Variable } & \multirow[t]{3}{*}{ Modalities } & \multicolumn{5}{|c|}{ Fisher exact test } & \multicolumn{3}{|c|}{ Univariate logistic regression test } \\
\hline & & \multicolumn{4}{|c|}{ Number of farmers } & \multirow{2}{*}{$\begin{array}{l}\text { Statistical } \\
\text { significance }\end{array}$} & \multirow{2}{*}{$\begin{array}{l}\text { Coefficients (St. } \\
\text { err.) }\end{array}$} & \multirow{2}{*}{$\begin{array}{l}Z \\
\text { values }\end{array}$} & \multirow{2}{*}{$\begin{array}{l}P \text { - } \\
\text { values }\end{array}$} \\
\hline & & Total & $\mathrm{P}$ & $\mathrm{R}$ & NP & & & & \\
\hline \multirow[t]{3}{*}{ District } & Medina Elhadj & 12 & 2 & 2 & 8 & \multirow[t]{3}{*}{$* *$} & \multirow[t]{3}{*}{$-0.95(0.63)$} & \multirow[t]{3}{*}{-2.26} & \multirow[t]{3}{*}{$0.02^{*}$} \\
\hline & Sare Bidji & 18 & 3 & 2 & 13 & & & & \\
\hline & Dioulacolon & 22 & 6 & 11 & 5 & & & & \\
\hline \multirow[t]{2}{*}{ Education } & Formal & 12 & 5 & 2 & 5 & \multirow[t]{2}{*}{ NS } & \multirow[t]{2}{*}{$0.43(0.67)$} & \multirow[t]{2}{*}{0.60} & \multirow[t]{2}{*}{0.50} \\
\hline & No formal & 40 & 6 & 13 & 21 & & & & \\
\hline \multirow[t]{3}{*}{ Activity } & Agriculture & 17 & 1 & 7 & 9 & \multirow[t]{3}{*}{ NS } & \multirow[t]{3}{*}{$-0.68(0.61)$} & \multirow[t]{3}{*}{-1.11} & \multirow[t]{3}{*}{0.30} \\
\hline & Livestock & 31 & 9 & 8 & 14 & & & & \\
\hline & Trade & 4 & 1 & 0 & 3 & & & & \\
\hline Type of livestock & Supplementation & 39 & 8 & 11 & 20 & NS & $1.07(0.68)$ & 1.15 & 0.37 \\
\hline & No supplementation & 13 & 3 & 4 & 6 & & & & \\
\hline Cattle breeds raised & N'Dama only & 13 & 4 & 6 & 3 & NS & $1.57(0.73)$ & 2.13 & $0.03 *$ \\
\hline & N'Dama and other breeds & 39 & 7 & 9 & 23 & & & & \\
\hline Preferred breed & N'Dama & 31 & 9 & 9 & 13 & & & & \\
\hline & Other breeds & & 2 & 6 & 13 & NS & $0.81(0.58)$ & 1.40 & 1.16 \\
\hline Preferred genetic improvement & $\begin{array}{l}\text { N'Dama/Gobra } \\
\text { crossbreeding }\end{array}$ & 18 & 3 & 4 & 11 & NS & $0.94(0.57)$ & 1.65 & 0.09 \\
\hline & N'Dama pure-breeding & 25 & 8 & 8 & 9 & & & & \\
\hline & $\begin{array}{l}\text { N'Dama/exotic } \\
\text { crossbreeding }\end{array}$ & 9 & 0 & 3 & 6 & & & & \\
\hline Other relationship with $\mathrm{CRZ}$ & Yes & 25 & 11 & 14 & 0 & $* * *$ & $-0.15(0.56)$ & -0.28 & 0.78 \\
\hline & No & 27 & 0 & 1 & 26 & & & & \\
\hline Member of an organization & CASE N'Dama & 11 & 11 & 0 & 0 & $* * *$ & $0.44(0.67)$ & 0.65 & 0.51 \\
\hline & Others & 28 & 0 & 9 & 19 & & & & \\
\hline & No & 13 & 0 & 6 & 7 & & & & \\
\hline Herd size (no) & $(24,50)$ & 14 & 1 & 4 & 9 & NS & & & \\
\hline & $(50,100)$ & 24 & 6 & 5 & 13 & & $0.01(0.007)$ & 1.76 & 0.07 \\
\hline & $(100,260)$ & 14 & 4 & 6 & 4 & & & & \\
\hline Distance breeder - CRZ $(\mathrm{km})$ & $(4-10)$ & 16 & 5 & 7 & 4 & $*$ & & & \\
\hline & $(10-15)$ & 27 & 6 & 5 & 16 & & $-0.02(0.05)$ & -1.98 & $0.05^{*}$ \\
\hline & $(15-25)$ & 9 & 0 & 3 & 6 & & & & \\
\hline Distance breeder - livestock market (km) & $(5-15)$ & 22 & 5 & 6 & 11 & NS & $-0.007(0.03)$ & -0.24 & 0.81 \\
\hline & $(15-25)$ & 18 & 3 & 6 & 9 & & & & \\
\hline & $(25-45)$ & 12 & 3 & 3 & 6 & & & & \\
\hline Distance breeder - dairy transformation & $(0-10)$ & 32 & 9 & 11 & 12 & * & $-0.02(0.05)$ & -1.23 & 0.19 \\
\hline unit $(\mathrm{km})$ & $(10-23)$ & 20 & 2 & 4 & 14 & & & & \\
\hline Animals sold per year (no) & $(0-4)$ & 34 & 4 & 9 & 21 & $*$ & $0.69(0.59)$ & 1.16 & 0.20 \\
\hline & $(4-10)$ & 18 & 7 & 6 & 5 & & & & \\
\hline Objectives of production & Milk objective & 8 & 0 & 2 & 6 & NS & $-0.59(0.56)$ & -1.05 & 0.20 \\
\hline & Others objectives & 44 & 11 & 13 & 20 & & & & \\
\hline
\end{tabular}

CASE N'Dama, Coopérative des Agroéleveurs Sélectionneurs du bovin N'Dama (Breeders Cooperative for N'Dama cattle breeding); $C R Z$, Centre de Recherche Zootechnique (Zootechnical Research Center); $P$, current participants to the breeding program; $R$, breeders who resigned from the breeding program; $N P$, breeders who never participated to the breeding program; no, number of animals; $N S$, not significant

$* p<0.05, * * p<0.01, * * * p<0.001$

link with animal sales rather than with the herd size directly. Indeed, large herds may be found on the side of breeders having adopted a distinct strategy, i.e., a commercial and crossbred-based one.
The congruence between their personal goals and the program's goal, which is to improve the animal's format and its conservation, is also expressed as a motive. Other related motives were the preservation of their culture, their way of life, 
Table 2 Correlations between explaining variables

\begin{tabular}{|c|c|c|c|c|c|c|c|c|c|c|}
\hline & District & $\begin{array}{l}\text { Cattle } \\
\text { breeds } \\
\text { raised } \\
\text { (N'Dama) }\end{array}$ & $\begin{array}{l}\text { Preferred } \\
\text { breed } \\
\text { (N'Dama) }\end{array}$ & $\begin{array}{l}\text { Objectives } \\
\text { of } \\
\text { production } \\
\text { (milk) }\end{array}$ & $\begin{array}{l}\text { Herd } \\
\text { size }\end{array}$ & $\begin{array}{l}\text { Distance } \\
\text { breeder - } \\
\text { CRZ } \\
(\mathrm{km})\end{array}$ & $\begin{array}{l}\text { Distance breeder } \\
\text { - dairy } \\
\text { transformation } \\
\text { unit }(\mathrm{km})\end{array}$ & $\begin{array}{l}\text { Animals } \\
\text { sold per } \\
\text { year (no) }\end{array}$ & $\begin{array}{l}\text { Preferred genetic } \\
\text { improvement } \\
\text { (N'Dama pure- } \\
\text { breeding) }\end{array}$ & $\begin{array}{l}\text { Presence } \\
\text { of } \\
\text { livestock } \\
\text { market }\end{array}$ \\
\hline District & 1 & $-0.45 * * *$ & $-0.42 * * *$ & $0.07^{\mathrm{NS}}$ & $-0.03^{\mathrm{NS}}$ & $0.30 *$ & $0.34 * *$ & $-0.04^{\mathrm{NS}}$ & $-0.26^{\mathrm{NS}}$ & $0.02^{\mathrm{NS}}$ \\
\hline $\begin{array}{l}\text { Cattle breeds } \\
\text { raised (N'Dama) }\end{array}$ & & 1 & $0.46^{* * *}$ & $-0.14^{\mathrm{NS}}$ & $0.21^{\mathrm{NS}}$ & $-0.07^{\mathrm{NS}}$ & $-0.15^{\mathrm{NS}}$ & $0.4^{*}$ & $0.31^{*}$ & $0.30 *$ \\
\hline $\begin{array}{l}\text { Preferred breed } \\
\text { (N'Dama) }\end{array}$ & & & 1 & $-0.20^{\mathrm{NS}}$ & $0.25^{\mathrm{NS}}$ & $-0.07^{\mathrm{NS}}$ & $-0.14^{\mathrm{NS}}$ & $0.01^{\mathrm{NS}}$ & $0.6^{* * *}$ & $0.10^{\mathrm{NS}}$ \\
\hline $\begin{array}{l}\text { Objectives of } \\
\text { production } \\
\text { (milk) }\end{array}$ & & & & 1 & $0.03^{\mathrm{NS}}$ & $0.20^{\mathrm{NS}}$ & $0.23^{\mathrm{NS}}$ & $0.009^{\mathrm{NS}}$ & $-0.31 *$ & $0.20^{\mathrm{NS}}$ \\
\hline Herd size & & & & & 1 & $-0.04^{\mathrm{NS}}$ & $0.21^{\mathrm{NS}}$ & $0.45 * * *$ & $0.13^{\mathrm{NS}}$ & $0.08^{\mathrm{NS}}$ \\
\hline $\begin{array}{l}\text { Distance breeder - } \\
\text { CRZ }(\mathrm{km})\end{array}$ & & & & & & 1 & $0.17^{\mathrm{NS}}$ & $-0.19^{\mathrm{NS}}$ & $-0.08^{\mathrm{NS}}$ & $0.06^{\mathrm{NS}}$ \\
\hline $\begin{array}{l}\text { Distance breeder - } \\
\text { dairy } \\
\text { transformation } \\
\text { unit }(\mathrm{km})\end{array}$ & & & & & & & 1 & $0.19^{\mathrm{NS}}$ & $0.19^{\mathrm{NS}}$ & $0.04^{\mathrm{NS}}$ \\
\hline $\begin{array}{l}\text { Animals sold per } \\
\text { year (No) }\end{array}$ & & & & & & & & 1 & -0.06 & $0.14^{\mathrm{NS}}$ \\
\hline $\begin{array}{l}\text { Preferred genetic } \\
\text { improvement } \\
\text { (N'Dama } \\
\text { pure-breeding) }\end{array}$ & & & & & & & & & 1 & $0.04^{\mathrm{NS}}$ \\
\hline $\begin{array}{l}\text { Presence of } \\
\text { livestock market }\end{array}$ & & & & & & & & & & 1 \\
\hline
\end{tabular}

$C R Z$, Centre de Recherche Zootechnique (Zootechnical Research Center); no, number of animals; NS, not significant

$* p<0.05, * * p<0.01, * * * p<0.001$

and their breeding practice. Studies of community-based breeding program models showed that farmers' interest considered in these programs is a prerequisite for their participation (Mueller et al. 2015).

On the contrary, farmers who were informed about the program and did not participate in the program stated the lack of adequacy of the program with their own milk production objectives as the main motive of their decision. The latter explanation is in line with the negative effect of milk production objective on participation as shown through logistic regression. In addition, milk production is negatively correlated with the stated preference for N'Dama breed $(r=-0.31)$ (Table 2). However, let us note that the negative correlation between milk production objective and the rearing of pure N'Dama herd is not statistically significant $(r=-0.14)$. This apparent discrepancy may be understood as pointing to the ongoing transformation of production systems in the zone, breeders showing a willingness to evolve towards milk production and considering N'Dama as not suited to this goal (Camara et al. 2019). In fact, the dairy production of N'Dama cattle rarely exceeds $2 \mathrm{~L}$ per day, which appears low compared with that of zebu cattle (Traoré et al. 2018). With such production performance gap, crossbreeding appears as a more effective and rapid strategy for improving cattle productivity, which has been particularly shown for milk in Africa (Traoré et al. 2018). From descriptive statistics, $88 \%$ of breeders mixing N'Dama and other genetic types were non-participants against $64 \%$ of current participants and $60 \%$ for resigning breeders (Table 1), although these differences were not significant $(p=0.06)$. Thus, the objective of milk production justifies the use of crossbreeding and modern production techniques by non-participants and resigning farmers (Camara et al. 2019).

\subsection{The ambiguous role of social bonds}

The content analysis highlights the role played in participation by existing relationships between the CRZ and breeders' families. "My family has been working with the CRZ since 1974, I grew up in these relationships and I have to continue and maintain them." These types of relationships put forward by the breeders are even the first motivation for maintaining in the program (Fig. 2). Statistical analysis confirmed this importance of the relationships between breeders, CRZ, and CASE N'Dama, distinguishing significantly between the three categories of breeders (Table 1). Some breeders also argued that 
the creation of the CASE N'Dama consolidated these relationships by the multiplication of meetings between them and the CRZ. These have significantly contributed to their decision to stay in the program. Such relationships that extension services can build with livestock keepers is widely recognized as enabling animal resource management and breeding programs implementation in development countries (Abdulai and Huffman 2005; Leroy et al. 2017). This points to the link between social bonds and "technology adoption," here translated as participation to the program (Bandiera and Rasul 2006). These relationships facilitate collaborative action between breeders and local research and extension units (Mueller et al. 2015).

Nevertheless, the mobilization of social bonds in the program outreach strategy appeared to play a dual role. Indeed, Dioulacolon district, which is home to the CRZ, harbors significantly more participants (Fisher's test), with 54\% of participating breeders (Table 1). This dominance shows that the initial recruitment failed at reaching farmers outside of the right-of-way area of the center. From narratives, it appears that the project's strategy for farmer recruitment rested on the social network of a major local stakeholder. Hence, a single breeder, native of Dioulacolon, had been instrumental in eliciting farmers' adhesion and had then been nominated by project managers as president of the so-created CASE N'Dama. Along the same idea, previous studies in Brazil have shown that extension and research agents can use families and friends as a means of social pressure to influence the farmers' behavior to adopt a technology (Borges et al. 2016).

This strategy of breeders' inclusion through social and family ties of an initial key stakeholder proved successful as it allowed for the creation of the cooperative. As mentioned above, this cooperative then helped establishing direct ties between farmers and the breeding program, as well as between farmers inside and outside of the concerned social network. Unfortunately, the fact that the past president is a native of Dioulacolon, i.e., the same district where the CRZ is located, contributed to limiting the geographical outreach of the program. A more open communication strategy indeed appeared here to have lacked, with non-participation being mainly explained by a lack of information (Fig. 2). From the statistical analysis, this reason has to be linked to the negative effect of distance on participation, with an especially weak representation in the program of farmers from Sare Bidji (logistic regression). Indeed, $61 \%$ of breeders living more than $10 \mathrm{~km}$ from the breeding nucleus have never participated in the program (Fisher's test) (Table 1). While this distance appears here as a physical barrier limiting the access to information (Abdulai and Huffman 2005; Hadush 2017), it also appears tightly related to the issue of social networks extension and how those are mobilized or not in the program design.

A second issue around this outreach strategy is that it introduced fragility in the program, due to the dependence on this particular social network. Indeed, some resigning breeders explicitly mentioned a direct pressure from the past president: "I resigned because my uncle, former president of the CASE N'DAMA and who was at the origin of my participation, asked me to do it." It may be observed also that $73 \%$ of the resigning breeders were from Dioulacolon (Fisher's test) (Table 1). This resignation movement was thus spurred by an initial conflict between the program and the past president, as further detailed below.

As a lesson learned, we may propose that the social network of key players should be mobilized more strategically to favor a geographical expansion of the program's basis. Also, the latter medium has to be kept in an inception role, enabling as soon as possible the building of direct ties with the program. Social dynamics at play in the constitution of the communitybased breeding program are then to recognize as complex and deserving in-depth analysis. Indeed, breeding programs crucially call for continuity, hence for a sustained effort and involvement of participants. Also, geographically wide participation is needed to ensure both genetic diversity and program's outreach. The social anchorage thus needs to be methodically monitored and strengthened to protect and optimize the common investment of participants.

\subsection{Institutional roots of trust and program's outreach}

The question of the relationship between breeders and the program may be framed as an issue of trust. Some breeders explained that their own observations of the good ability of the CRZ to conduct a breeding nucleus have built up their trust and reinforced their willingness to participate. On the contrary, complaints on husbandry were also given as a motive for resignation. Hence, one actor stated: "I did not see any interest in staying in the program because the animals I introduced stayed for two years without calving unlike those in my herd." Others mentioned problems of too high mortalities in the nucleus. The concerned breeders deem that the CRZ has inadequate human resources, knowledge, and infrastructure to raise N'Dama cattle. One farmer considered the center manages herds with "civil servant hours," i.e., working from 8 am to $4 \mathrm{pm}$, "while the conduct of animals on pasture requires a greater availability."

Besides possible gaps in animal management, these facts may also be expected consequences of the inclusion of trypanotolerance as a trait for animal selection. Indeed, to include this trait in the breeding design, animals are reared under a trypanosomian stress where trypanocides are used only curatively, in severe cases. This requirement of the breeding design may cause degradation of the general condition of the animals and decreased reproductive performances and even mortalities. A similar selection design has been applied in Gambia with the major difference that animals subjected to the selection all belong to the International Trypanotolerance 
Centre (ITC) (Bosso et al. 2007). Therefore, although calving interval was longer in the nucleus of Gambia compared with that in Kolda (20.5 months vs. 17.6 months) (Agyemang et al. 1997; Camara 2012), this did not affect the trust between farmers and the program in the case of Gambia.

Some resigning breeders also reported an organizational problem of the breeding program as the main motive to resign. While some indicated cases of misconduct (e.g., "discrimination made by the CRZ and CASE N'DAMA in the dissemination of the N'Dama sire"), a more constant case was made of the absence of compensation, i.e., "promised veterinary monitoring of our herds to compensate for the milk our cows produce in the breeding nucleus." During the test phase of the opening of the breeding nucleus to the farmers' herds in the 1990s, each farmer received 20,000 CFA (30.5 euros) per month and per cow, to compensate for the lost milk. The shift towards a community-based program through the creation of CASE N'Dama was then made with the idea that the program should be organized and led by breeders. Therefore, financial compensation was felt as contrary to this spirit and threatening the sustainability of the program. Contrary to this idea, in another context, several studies in Tanzania, Ethiopia, and Uganda reported that a subsidy given to farmers has increased the adhesion rates to breeding programs, contributing to their success (Roschinsky et al. 2015). Finally, while the impact of dependence on external funding on sustainability is a valid concern, the response consisting of canceling the compensation scheme proved detrimental to the project. Solutions may thus be sought in the provision of compensation by the cooperative, then mainly funded through members' subscription.

The issue of animal ownership appeared limiting in one more aspect, i.e., the shared ownership of the herd among a family. Interestingly, in such cases, breeders affirmed their personal adhesion to program's objectives but were stopped by the other members of the family, who had the power to do so due to the shared property rights.

Therefore, the issue of trust and participation is more particularly tied to the institutional arrangement around animal ownership, the distribution of benefits among participants, and the compensations to provide to contributing breeders. Indeed, since pure-breeding programs deliver results in the long run, the short- and medium-term expectations of farmers must be met through subsidies, compensating for their investment in terms of time, labor, or animals. The need to submit animals to a trypanosomian stress in the selection process makes these questions even more central to the success of the program, which then appears as a gap in the design of the Casamance N'Dama breeding program. The adequacy between the program and local property rights on livestock has then to be tailored through a careful consultation of breeders, which could have avoided in this case the neglect of shared property rights. The balance to be sought has then to consider the costs and benefits as well as consequences on viability of different strategies, going from the simple acquisition of cattle by the external project to the individual compensation for the provision of animals without a transfer of ownership, and including various possible levels of collective property rights or cost-sharing schemes in delivering individual compensations.

\subsection{Competition, conflicts, and power relationships}

Some breeders reported as a motive for non-participation that they are beneficiaries of activities in "another program with objectives that are opposed to those of the breeding program." Indeed, associations and breeders' organizations are often set up by NGOs to facilitate and make their actions visible (Charbonneau and Poinsot 2008). By doing so, these associations would prohibit their members from participating in activities developed by other programs and projects that could overshadow the activities of their donors. As already described by Castaneda (2005), this strategy of donors appears as an instrumentalization of peasant organizations for the project's benefit. This element clearly appears from the variable "membership in an organization" (Table 1), of which the link with the 3-modality participation variable appears tautological once light has been shed on this social reality: all members of an association are requested not to adhere to other associations. In the present case, resigning breeders, hence former members of CASE N'Dama, were contacted by another $\mathrm{NGO}$ at the time of their resigning movement to form a new group still under external funding. The presence of farmers not belonging to any association both among those who never participated and those who resigned explains the lack of statistical effect detected through regression analysis with the 2modality participation variable.

The narrative analysis disclosed a diversity of motives behind the conflict and resigning movement. The different natures of conflicts between breeders, CASE N'Dama, and the CRZ indicate a deep malfunction of the breeding program. The positive dynamic of a network of actors is a necessary basis for the adoption of technical innovations (Triomphe et al. 2016). The conflicts between the breeders and their cooperative appear as resulting from project interference in the permanent struggle between breeders for leadership and recognition. Indeed, the past president had been nominated by the project with the overall agreement of participants who had been in majority brought there through his social network. After 2 years, an extraordinary general assembly of CASE N'Dama was convened at the request of breeders to provoke early elections, which led to the nomination of a new president and the resignation of the past president as well as of his supporters. According to converging breeders' narratives, it appears that this general assembly had been requested based on repeated complaints from project managers about the literacy level of the past president which was deemed insufficient 
to participate in meetings and represent the cooperative and the project. Let us note that the newly elected president is indeed a retired teacher with the needed literacy level. Leadership in a community obviously results from complex endogenous processes, which here mainly refers to the traditional Fulani leadership, held by the so-called Jarga, i.e., the owner of a large herd, who integrates around him several small breeders, providing them support. As a matter of fact, in a community with a majority of illiterate members, the criteria of education as requested to hold collective responsibilities is a potential source of social inadequacy and conflict. The lack of relevance of education as a criterion may be supported by the lack of significant effect of this factor on the participation in the breeding program (Table 1).

This case study may come at first sight as an example of how power struggles and the manifestation of power relations within communities may constitute an important limit of peasant cooperatives for the adoption of innovations. Such struggles have been shown to possibly lead to the abandonment of the proposed innovation (Babeau and Chanlat 2011). However, in-depth analysis joining narratives and statistical approaches helped us disentangling the complex determinants of these conflicts, establishing the share of responsibility in this failure that has to be ascribed to project design and strategy.

\subsection{Methodological insights}

The originality of this work lies in its in-depth analysis of participation to a breeding program tackled through a mixed methodology, joining statistical and narrative analysis. Referring to the taxonomy of mixed methods along their structure, function, and process, as proposed by Palinkas et al. (2011), we may qualify the present approach as (i) in terms of structure, giving an equal role to its qualitative and quantitative components; (ii) in terms of function, as mobilizing those in convergence and complementarity, each bringing a specific perspective on the same topic, sometimes on the same fact to analyze; and (iii) in terms of process, merging results, through cross-validation or joint interpretation. Yet, both statistical and narrative approach are mobilized here as interpretive approaches, not aiming at an inference from the sample results to a population. Both approaches are assigned here the same role of in-depth understanding, forgoing a request for breadth that is the role commonly assigned to statistical analysis in mixed method literature (Flyvbjerg 2006; Palinkas et al. 2011). Hence, throughout this analysis, statistical results could guide and complement interpretation of narratives, while narratives on several occasions proved necessary in making sense from otherwise statistically significant but "mute" results. None of the approaches, used as a standalone method, would have delivered the required understanding, i.e., one that is both locally actionable and prone to identify crucial factors in participation to be explored further.

The complementarity between statistical and narrative approaches also lies in the fact that each method directs the analysis towards distinct components of the human behavior under scrutiny. Indeed, through its attempts to identify overarching and systematic effects, statistical analysis may be described as focusing on a deterministic approach of innovation, considering actors' behavior as partly determined by the tested factors. As for narrative analysis, it highlights events and motives, hence a part of randomness and actors' strategies, which then refers to their degree of freedom within a partly determined framework (Crozier and Friedberg 1977). Hence, the mixed method provides an explanatory framework that helps to deepen the understanding, interpretation, and validity of results. Interestingly, St. Pierre (2014) points out that "confusion and contradiction" are not uncommon when a researcher uses both methods simultaneously in the same study. As analyzed by Baškarada and Koronios (2018), such contradiction directly results from the poor or unclear integration of qualitative and quantitative approaches. In our case, such apparent contradictions appeared, as in the case of the effect of herd size, which could be clarified through a joint interpretation of these results.

\subsection{Highlight: a matter of trust}

The adequacy of breeders' objectives, whether based on social, cultural, or economic factors (presence of livestock markets or dairy transformation units), with those of the breeding program is an important determinant of membership to the program but not sufficient. Social, family, and institutional relationships have guided the decision of the breeders throughout the development of the program. Thus, the breeders mentioned the same social or family reasons to justify their participation or their resignation from the program. For the promotors, these ties (between breeders, CRZ, and CASE N'Dama), built on trust, should be assets to promote adhesion. Paradoxically, they constituted fragility for the breeding program. Finally, the reasons for conflicts mentioned as having led to resignation result from these social and institutional problems and the breeding program conduct. These conflicts show a lack of trust between stakeholders, a distrust more precisely targeting the management of the program, the organization of CASE N'Dama, and the husbandry practices in the breeding nucleus. Thus, to be effective and to avoid or limit conflicts, sustainable management of the breeding program must integrate the tools of local and traditional governance that are socially and culturally close to the breeders. It must also rely on a compensation mechanism for breeders who have agreed to put their herds at the disposal of the breeding nucleus. A governance promoting trust between 
partners within recognized institutions hence appears as the fundamental condition for the sustainability of the breeding program itself and also, in the wider picture, for the sustainability of livestock production in a region subject to important social, economic, and environmental changes.

\section{Conclusion}

The present study is the first to take advantage of complementary statistical and narrative analyses to provide a detailed account of participation in a livestock breeding program. Building on methodological literature about mixed methods and case studies, it rigorously integrates numerical and textual approaches to highlight actors' behavior, in their determined and strategical dimensions. As regards participation to livestock programs, it more particularly highlights the complexity of social issues, pinpointing crucial levers of improvement, i.e., the management of animal property rights between the nucleus management and the participating breeders, the legitimacy of participants' representatives in cooperatives, and the strategic mobilization of members social networks, in face of classical determinants of adoption that are distance or production systems features. Also, adding on previous works of the authors (Camara et al. 2019), this study highlights the need to take better account of the dynamics of production systems within a changing context then paying sufficient attention to the objectives, preferences, and ongoing strategies of the breeders for the future.

Acknowledgments The authors wish to thank all participating farmers and investigators. They acknowledge the support of the West Africa Agricultural Productivity Program (WAAPP), the Senegalese Institute of Agricultural Research (ISRA), and Wallonie-Bruxelles International, Belgium. The authors are grateful to the journal's editor and the anonymous referees for useful suggestions on earlier versions of this manuscript.

\section{Compliance with ethical standards}

Conflict of interest The authors declare that they have no conflict of interest.

\section{References}

Abdulai A, Huffman WE (2005) The diffusion of new agricultural technologies: the case of crossbred-cow technology in Tanzania. Amer J Agr Econ 87:645-649. https://doi.org/10.1177/0160017604266026

Agyemang K, Dwinger R, Little D, Rowlands GJ (1997) Village N'Dama cattle production in West Africa: six years of research in The Gambia. International Livestock Research Institute, Nairobi, Kenya, and International Trypanotolerance Centre, Banjul, The Gambia

Babeau O, Chanlat JF (2011) Déviance ordinaire, innovation et gestion. Rev Française Gest Lavoisier 37:35-50 doi: halshs-00641100
Bandiera O, Rasul I (2006) Social networks and technology adoption in Northern Mozambique. Econ J 116:869-902. https://doi.org/10. 1111/j.1468-0297.2006.01115.x

Baškarada S, Koronios A (2018) A philosophical discussion of qualitative, quantitative, and mixed methods research in social science. Qual Res J 18:2-21. https://doi.org/10.1108/QRJ-D-17-00042

Borges JAR, Tauer LW, Lansink AGJMO (2016) Using the theory of planned behavior to identify key beliefs underlying Brazilian cattle farmers' intention to use improved natural grassland: a MIMIC modelling approach. Land Use Policy 55:193-203. https://doi.org/ 10.1016/j.landusepol.2016.04.004

Bosso NA, Corr N, Njie M et al (2007) The N'Dama cattle genetic improvement programme: a review. Anim Genet Resour Inf 40: 65-69. https://doi.org/10.1017/S1014233900002200

Camara Y (2012) Analyse génétique des performances zootechniques des bovins de race N'Dama et étude du système d'amélioration génétique à noyau ouvert. Institut Vétérinaire et Agronomique Hassan II, Rabat, Maroc

Camara Y, Moula N, Sow F et al (2019) Analysing innovations among cattle smallholders to evaluate the adequacy of breeding programs. Animal 13(2):417-426. https://doi.org/10.1017/ S1751731118001544

Castaneda D (2005) Les organisations d'éleveurs et de pasteurs au Sénégal. In: Reflexions et Perspectives/Institut Sénégalais de Recherche Agricole (ISRA), vol 6, p 64

Charbonneau M, Poinsot Y (2008) De l'individuel au collectif: Les modes de gestion de l'élevage dans la puna péruvienne. Etud Rurales 181:39-60. https://doi.org/10.4000/etudesrurales.8614

Crozier M, Friedberg E (1977) L'acteur et le système, Edition du Seuil, Points Essais N ${ }^{\circ} 248$, Paris, France

Diop M, Sissokho MM, Niang S (1993) Mise en Place D’un schéma de sélection à noyau Ouvert pour l'amelioration génétique du taurin Ndama : Resultats du "Screening" des vaches exceptionnelles dans le département de Kolda (Sénégal).

Fall A, Diop M, Sandford J et al (1982) Evaluation of the productivities of Djallonke sheep and N'Dama cattle at the Centre de Recherches Zootechniques, Kolda, Senegal. In: ILCA Research Report 3. ILCA (International Livestock Centre for Africa), Addis Ababa, Ethiopia $70 \mathrm{pp}$

Flyvbjerg B (2006) Five misunderstandings about case-study research. Anthropol Notebooks 12:219-245. https://doi.org/10.1177/ 1077800405284363

Hadush M (2017) Exploring farmers' seasonal and full year adoption of stall feeding of livestock in Tigrai region. Ethiopia Econ Agric 085: 919-944. https://doi.org/10.5937/ekoPolj1703919H

Kosgey IS, Baker RL, Udo HMJ, van AJAM (2006) Successes and failures of small ruminant breeding programmes in the tropics: a review. Small Rumin Res 61:13-28 doi: 0921-4488

Leroy G, Baumung R, Notter D et al (2017) Stakeholder involvement and the management of animal genetic resources across the world. Livest Sci 198:120-128. https://doi.org/10.1016/j.livsci.2017.02.018

Limon G, Lewis EG, Chang YM et al (2014) Using mixed methods to investigate factors influencing reporting of livestock diseases: a case study among smallholders in Bolivia. Prev Vet Med 113:185-196. https://doi.org/10.1016/j.prevetmed.2013.11.004

Mankad A, Loechel B, Measham PF (2017) Psychosocial barriers and facilitators for area-wide management of fruit fly in southeastern Australia. Agron Sustain Dev 37:1-12. https://doi.org/10.1007/ s13593-017-0477-z

Mueller JP, Rischkowsky B, Haile A et al (2015) Community-based livestock breeding programmes: essentials and examples. J Anim Breed Genet 132:155-168. https://doi.org/10.1111/jbg.12136

Palinkas LA, Aarons GA, Horwitz S et al (2011) Mixed method designs in implementation research. Adm Policy Ment Health Ment Health Serv Res 38:44-53. https://doi.org/10.1007/s10488-010-0314-z 
R Core Team (2017) R: A language and environment for statistical computing. R Foundation for Statistical Computing, Vienna, Austria. https://www.R-project.org/

Roschinsky R, Kluszczynska M, Sölkner J et al (2015) Smallholder experiences with dairy cattle crossbreeding in the tropics: from introduction to impact. Animal 9:150-157. https://doi.org/10.1017/ S1751731114002079

Senger I, Borges JAR, Machado JAD (2017) Using structural equation modeling to identify the psychological factors influencing dairy farmers' intention to diversify agricultural production. Livest Sci 203:97-105. https://doi.org/10.1016/j.livsci.2017.07.009

St. Pierre EA (2014) A brief and personal history of post qualitative research toward post inquiry. J Curric Theor 30:2-19

Stear MJ, Bishop SC, Mallard BA, Raadsma H (2001) The sustainability, feasibility and desirability of breeding livestock for disease resistance. Res Vet Sci 71:1-7. https://doi.org/10.1053/rvsc.2001.0496

Strauss A, Corbin J (1990) Grounded theory, procedured, canons and evaluative criteria. Qual Sociol 13(1):3-21. https://doi.org/10. 1007/BF00988593
Suvedi M, Ghimire R, Kaplowitz M (2017) Farmers' participation in extension programs and technology adoption in rural Nepal: a logistic regression analysis. J Agric Educ Ext 23:351-371. https://doi. org/10.1080/1389224X.2017.1323653

Traoré SA, Reiber C, Zárate AV (2018) Productive and economic performance of endemic N'Dama cattle in southern Mali compared to Fulani Zebu and their crossbreds. Livest Sci 209:77-85. https:// doi.org/10.1016/j.livsci.2018.01.013

Triomphe B, Floquet A, Letty B et al (2016) Mieux évaluer et accompagner l'innovation agricole en Afrique. Leçons d'une analyse transversale de 13 cas d'études. Cah Agric 25:1-11. https://doi. org/10.1051/cagri/2016050

Windows (2016) Microsoft Office: Excel version 2016

Publisher's note Springer Nature remains neutral with regard to jurisdictional claims in published maps and institutional affiliations. 